CAHIER DE RECHERCHE \#1103E

Département de science économique

Faculté des sciences sociales

Université d'Ottawa
WORKING PAPER \#1103E

Department of Economics

Faculty of Social Sciences

University of Ottawa

\title{
On the Dual Nature of Weak Property Rights*
}

\author{
Louis Hotte ${ }^{\dagger}$, Randy McFerrin ${ }^{\ddagger}$ and Douglas Wills ${ }^{\S}$
}

April 2011

\footnotetext{
* This paper has benefitted from comments by seminar participants at the University of Ottawa and Université de Rouen. This work was partly supported by a research grant from the SSHRC.

${ }^{\dagger}$ Department of Economics, University of Ottawa, 55 Laurier E., Ottawa, Ontario, Canada, K1N 6N5; Email: louis.hotte@uottawa.ca.

${ }^{\ddagger}$ New Mexico State University; Email: mcferrin@nmsu.edu.

§ University of Washington; Email:dtwills@u.washington.edu.
} 


\begin{abstract}
In the natural resource literature, conventional wisdom holds that weak property rights will cause a resource to be over-exploited. This is because weak property rights are typically perceived as a problem of input exclusion. In this paper, we first present evidence to the effect that weak property rights often take the form of contestable outputs - or output theft - and that this has an impact on resource use. We then propose a theoretical model of natural resource use under generally weak property rights - or weak state presence - when resource users face the dual problem of input exclusion and output appropriation. We show that introducing the possibility that outputs can be contested acts as an output tax, with the added twist that resource users effectively determine the level of the tax. This tax has a depressive effect on input use. As a result, whether the resource is under-or over-exploited in equilibrium will depend on the relative severity of output appropriation and input exclusion problems when property rights are generally weak.
\end{abstract}

Key words: Natural Resources, Property Rights, Trespass, Theft, Over-Exploitation, UnderExploitation.

JEL Classification: K11, K42, Q2, N50, O13.

\title{
Résumé
}

Dans la littérature sur les ressources naturelles, on associe généralement une déficience dans les droits de propriété avec une sur-exploitation de la ressource. Ceci s'explique par le fait que la déficience est surtout perçue comme une exclusion incomplète des utilisateurs de la ressource. Dans ce travail, nous présentons plusieurs cas où le problème de propriété porte tout autant sur l'appropriation des biens produits par les utilisateurs, ou le vol. Un modèle théorique est proposé dans lequel il est démontré que ce problème mène plutôt à une sous-utilisation de la ressource. Ainsi, dans les régions où les droits de propriété sont mal protégés de manière générale, souvent dû à un état faible, on doit s'attendre à ce que les deux types de problèmes coexistent. Il sera dès lors nécessaire de comparer la sévérité des deux déficiences de protection afin de déterminer si la ressource sera sur-ou sous-exploitée à l'équilibre.

Mots clés: Ressources naturelles, Droits de propriété, empiètement, vol, sur-exploitation, sous-exploitation

Classification JEL: K11, K42, Q2, N50, O13. 


\section{Introduction}

In the natural resource economics literature, weak property rights are typically presented as the fundamental cause of resource overexploitation. The basic argument can be traced back to the pioneering work of Gordon (1954), who explained that in the absence of ownership rights to a fishery, all fishers enjoy a free access and this yields an equilibrium with excessive input use and low rents. This standard story has led many to equate weak property rights with resource overexploitation.

Now as Gaudet, Moreaux and Salant (2002) justly point out, the convention in natural resource models has been to "assume that everything extracted under the rule of capture is marketed immediately", as Gordon (1954) did. Implicit with this assumption is the fact that there are no property right issues regarding the extracted resource, that is, output appropriation is not being contested. This assumption is not innocuous. To illustrate, take two gold prospectors on a creek, John and Peter. Under the rule of capture, on one hand, the gold lying at the bottom of the creek belongs to no-one, but the gold nugget that is found belongs to its founder. John and Peter are therefore racing to find gold in the creek. Under immediate marketing, on the other hand, John - and everyone else standing between the creek and the market, for that matter - does not dispute the fact that the gold scooped up by Peter belongs to Peter. Now if property rights are weak because of a weak state presence, it is reasonable to assume that property rights may be generally weak, not just in terms of exclusive access to a resource. Consequently, bringing gold to the market may not be so straightforward.

More generally, in the "Gordon setting", a situation of weak property rights over unextracted resources co-exists with the presence of strong property rights over extracted resources. This may have been a fair representation of the problems facing cod fishers in Newfoundland in the 1950s. In many other contexts of resource use, however, this co-existence of weak and strong property rights does not depict reality well, especially under a weak state presence. Resource users are often faced with a dual enforcement problem: not only is access to the resource imperfectly controlled, but some of the output produced may also be appropriated, or stolen, by others. In the light of this dual enforcement problem, the purpose of this paper is to analyse the consequent decisions of natural resource users.

We begin by presenting evidence of dual enforcement problems taken from existing case studies. This evidence is used to set-up a simple two- 
dimensional analytical framework helpful in comparing the cases in terms of the relative importance of each enforcement problem. A theoretical model is then proposed which accounts for the strategic behavior of three types of agents: a resource manager as a leading resource user and output appropriator; trespassers as illegitimate or fringe resource users; and thieves as illegitimate output appropriators.

We show that in the presence of generally weak property rights, theoretical predictions regarding resource use can be drastically different from the tragedy of the commons story. Indeed, the presence of output theft causes the resource to be under-exploited. This is because output appropriation by others acts as a tax on output, with the added twist that the tax level is endogenously determined by resource users. As a result, when enforcement is partial for both input exclusion and output appropriation, whether the resource ends up being under- or over-exploited will depend on the relative severity of each enforcement problems. For the particular case of a free-access resource, the presence of theft actually induces resource conservation. The flip side is that the introduction of stricter property enforcement measures against theft that neglect the problem of free access to inputs may cause the resource to be overused and even lead to its depletion. Comparative static experiments are performed by varying the degree of property rights enforcement over both input access and output appropriation which are used to provide insight into various case studies.

The paper is organized as follows. In section 2, existing case studies are first exposed as supporting evidence for the presence of a dual enforcement problem. Other cases are also presented where it is argued that one or the other enforcement problem may prevail at varying degrees. To fix ideas, a first theoretical model is proposed in section 3 in which only the problem of output appropriation is present. This is followed by a full model of dual enforcement in section 4 . A characterization of possible equilibrium types is performed in section 5, which is then used in section 6 to provide new insight into each case discussed in section 2 . Section 7 concludes with a discussion of possible avenues of research.

\section{Evidence of dual enforcement problems}

In the classical story of the tragedy of the commons, no user has the right or the ability to exclude others from exploiting a resource. And yet, it is assumed that users have perfectly and costlessly enforced rights over the goods 
being produced with the resource. In this section, we present evidence to the effect that both types of property enforcement problems often prevail simultaneously. This will set the stage for the development of a theoretical model in the following section and show that this has important implications for our understanding of natural resource use.

In general, property rights must not only be defined and measurable, but enforced as well. In some settings, enforcement is however notoriously difficult to achieve. A good example of such a situation is the 1848 California Gold Rush. Prospectors discovered gold shortly before the territory was ceded to the United States and well before any effective legal system could be put in place. The latter didn't matter, in any case, as most soldiers sent into the area quickly deserted the army to search for gold. The area was literally without any enforceable laws. Umbeck's (1981) excellent study of this period documents the rise of property rights through private contracts and threats of violence.

The natural resource being exploited during the Gold Rush must be seen as a large track of territory over which various gold deposits were (suspected to be) present but their precise locations were unknown. The exploitation of this natural resource therefore required exploration efforts as inputs. Now in the absence of any enforcement of exclusion from the territory, the resource was subject to an open access regime of exploitation. In the Gordon (1954) spirit, the consequence was (probably) an excessive use of inputs, or exploration efforts; thus the Rush labeling.

It is revealing that Umbeck's study focused exclusively on the efforts expended to define and defend mineral rights. Although he does not present it in those terms, one must conceptualize this as a problem of exclusion over the output from a resource. Indeed, exploration efforts produce identification of gold deposits as outputs. Umbeck thus reports on how difficult it was for an explorer to appropriate the fruits of his efforts. Here, a miner faced the dual problems of first finding a gold deposit before others did and second effectively stake and defend a mining claim.

An analogous situation evolved a few decades later on the US western plains with the rise of the range cattle industry. This era began around 1880 and lasted until the mid to late 1890s. The distinguishing characteristic of this industry was the use of public domain land for cattle grazing. Huge cattle ranches actually owned very little land; they would simply release their 
cattle onto the public domain for grazing and then round up the cattle twice a year for branding and shipping.

Ranchers faced the same set of dual problems as the California miners. Here, grazing land is the natural resource, number of calves to raise is the input, and number of grown cattle is the output. First, given that the grazing lands were in the public domain, they could not legally exclude others' input use. Thus, there were competitors for the land - other cattle ranchers, sheep farmers, and homesteaders. As such, they had to expend resources, in both legal and extra-legal activities, to exclude others from using the ranges. In contrast with the miners' situation, the resource was thus subject to some enforcement of exclusion over input use, though costly and incomplete. Second, while ranchers legally owned their cattle, there were little effective government forces to help protect cattle from theft on the ranges. Therefore, ranchers had to also expend resources to prevent cattle rustling, that is, excluding others from appropriating the output.

Just as with the California miners, ranchers developed institutions to deal with the lack of effective property rights. Economic historians, such as Anderson and Hill (1975), document the rise of these institutions to control resource use under imperfect exclusion rights. A system of informal constraints, known collectively as codes of the west, and range rights, based upon the doctrine of prior appropriation, evolved to address negative externalities associated with open range ranching. Additionally, western cattlemen created institutions such as cattlemen's associations to enforce the code, protect established range rights, and detect stock theft. Fundamentally, stock associations functioned equivalently to a police force in the face of weak protection from the state.

Academic research on the range cattle industry has focused, almost exclusively, on the role of the public domain and the incentives created for ranchers to over-exploit the grasslands. The impact of cattle rustling on resource use has received little attention. Yet, it is widely recognized that rustling was an important problem (McFerrin and Wills 2007). In fact, one historian, Weaver (2003), argues that the main purpose of cattlemen's associations was to combat rustling.

It may be argued that one notable difference between the Gold Rush and cattle industry examples resides in the fact that in the latter, one notes the presence of a partial enforcement in both dimensions while in the former, exclusion over input access was practically nonexistent. Conceptually, one can 
imagine any combination of enforcement levels in both dimensions ranging from nonexistent to partial or complete. Suppose then that exclusion enforcement levels over input access and output appropriation can be represented by parameters $\lambda$ and $\theta$ respectively, both taking on real values between 0 and 1. A value of 0 corresponds to the absence of exclusion while a value of 1 denotes perfect exclusion. In-between, enforcement of exclusion is partial and increasing in the respective parameter value. Under this framework, the enforcement levels corresponding to the Gold Rush and the open range in the American West can be approximately represented as in figure 1 by the points labeled GR and ORW respectively.

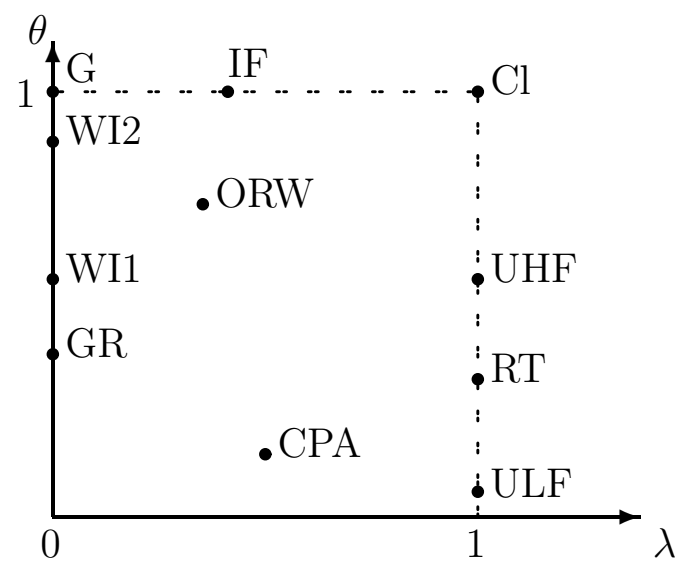

Figure 1: Dual property enforcement levels

The standard economics textbook case of production and trade in the absence of property enforcement issues is represented by $\lambda=\theta=1$ in figure 1 and is labeled $\mathrm{Cl}$ for Classical. Gordon's (1954) story, on the other hand, was meant to illustrate the problem of cod fishing in the North Atlantic. In that setting, it is assumed that a large number of fishers can freely access the open sea fishery, thus corresponding to an absence of input exclusion enforcement, or $\lambda=0$. On the other hand, output theft is not an issue. Once a fisher's catch is brought to shore, it is immediately sold to market in its entirety, thus corresponding to perfect enforcement against theft, or $\theta=1$. This situation corresponds to the point labeled $\mathrm{G}$ in figure 1 . The other points appearing in figure 1 are explained by the following additional 
cases.

Cases of dual exclusion problems can also be found in developing countries today where resource users operate under a weak state presence. Mbogo (2009) documents the case of common pasture farmers in semi-arid regions of Africa, who face situations akin to those of open range cattlemen in the American West reported above. They formed cooperative agreements for the management of common pasturage, but the threat of violent cattle theft increased to a level where they now avoid these grazing districts altogether. This case would arguably correspond to the point labeled CPA in figure 1. One notes that in this case, the presence of theft is reported to result in a complete failure to exploit the resource.

In other settings, access to the resource is not subject to contestation but output theft is still a major problem, that is, $\lambda$ is close to 1 but $\theta$ is clearly below 1. The use of undeveloped land for urban farming provides a good case in point. According to some accounts, crop theft acts as a major impediment to the development of urban agriculture, even though it can help feed the urban poor. Studies like those of Mboganie-Mwangi and Foeken (1996), Ellis and Sumberg (1998) or Bryld (2003) invariably report that this is the case for plots of land located far away from the homes. We therefore illustrate the case of urban land farming by the point labeled ULF in figure 1. On the other hand, land adjacent to the home is still sometimes farmed, despite imperfect enforcement against theft. The case of urban home farming is thus illustrated by the point labeled UHF in figure 1. Similarly, agricultural theft in rural areas is a significant problem today in many parts of the world. According to a recent publication by the Technical Centre for Agricultural and Rural Cooperation (CTA), "Agricultural theft is a serious problem for many ACP (Africa, Caribbean and Pacific group) producers, causing massive losses and prompting some farmers to give up altogether. [... A Trinidadian farmer with a herd of 120 cows invested in a milking parlour and a dairy processing plant. Within 2 years every animal had been stolen. Today, the farm has been cut up into building lots." (Spore 2009) The article reports that theft affects all types of agricultural productions, from coffee cherries to vanilla beans and livestocks. Fafchamps and Minten (2006) relatedly provides evidence that crop theft increases with transitory poverty. Similarly, a Zimbabwean newspaper article attributes the large drop in cattle farming in the past ten years to rampant rustling. (Sakala 2011) One may therefore think of rural theft problems as falling anywhere between 
the Urban Home Farming and the Urban Land Farming cases, as illustrated by the point labeled RT in figure 1.

Inshore fisheries are also often fraught with problems of imperfect enforcement. Wennersten (2007), for example, recounts the history of policing problems and illegal oyster fishing that dragged on for over two centuries on the Chesapeake Bay. According to Wennersten's accounts, the problem was in large part due to insufficient policing resources, a form of state weakness with $\lambda$ much below 1 . The history of lobster harvesting in Maine as reported in Acheson (1988) similarly describes a situation of partial exclusion enforcement issues. Output theft, however, did not seem to be a serious problem for inshore fishers, an indicator of state strength with theta close to 1 . In any case, an inshore fishery would correspond to the point labeled IF in figure 1.

A final case of interest in that of the whaling industry of the 18th and 19th century as recounted by Ellickson (1991). Contrary to inshore fishers but similarly to cod fishers, whalers operated in the open seas and thus could hardly count on any state presence. For technological reasons and contrary to cod fishers, whalers did however face a problem of output appropriation. Indeed, it was not uncommon that a whale would slip away from the first ship that spotted and hunted it, only to be easily picked up, once weakened or dead, by another whaler. Now given that the bulk of the cost of input efforts in whale fishing is the time spent locating a whale, much more than the actual hunting phase - a whaling voyage could last up to four years - it is not surprising that this often led to serious ownership contestations over dead whales. Ellickson argues that the international whaling community was a surprisingly close-knit community and that they therefore managed to develop ownership norms for previously hunted loose whales which where reasonably successful in rewarding the effort of its initial founder. They were, however, never successful at solving the problem of free access to whaling efforts. This situation is actually quite similar to that of the Gold Rush described above. In figure 1, points WI1 and WI2 represent the whaling industry respectively before and after the adoption of norms regarding whale capture. Given that input effort exclusion remained unenforced, i.e. $\lambda=0$, our model will predict that the adoption of the norm may have contributed to the depletion of whale stocks.

With the above cases in mind, we shall propose a model of resource use when enforcement against both input exclusion and output appropriation can both vary as per figure 1 . 


\section{A model of theft and natural resource use}

Let $y$ denote the output produced from a (natural) resource. Typically, output quantities depend on the size of the resource stock and various input quantities such as labor and physical capital. But in order to simplify the analysis, we assume the size of the resource stock to be fixed throughout and that output depends on a single measure of total input effort denoted $X$. We thus have $y=f(X)$, where function $f$ is increasing and concave.

It is assumed that inputs $X$ have constant unit costs $c$ and output $y$ fetches a constant unit price $p$. Net profits from the resource are thus given by $\pi=p f(X)-c X$ and the (first-best) efficient input quantity $X^{*}$ is defined by the condition that equates marginal revenues and costs; that is,

$$
p f^{\prime}\left(X^{*}\right)=c .
$$

The efficient input quantity will be chosen by the resource manager, provided that property rights can be perfectly and costlessly defined and enforced. But such ideal conditions are rarely met in practice, as outlined in section 2. We will therefore consider two major types of property enforcement problems that resource managers were reported to face: One is the exclusion of unauthorized, or unwanted, exploiters of the resource. The other relates to the final appropriation of outputs by non-exploiters. For convenience, we shall refer to the first problem as trespass and the second as theft.

It should be noted that for our purpose, it is inconsequential whether the resource manager is a farmer, a state bureaucrat, the agent of a local collective or firm, or even a locally powerful thug. In the case of a common property resource, for instance, trespassers and thieves may be members of the collectives themselves who break its own rules. ${ }^{1}$ In any case, the resource manager is defined as the person with de facto property rights in the sense that trespassers and thieves will be punished if caught.

For clarity of exposition and since most readers tend to be familiar with the problem of input exclusion, we begin with the case of output appropriation problems only in this section. ${ }^{2}$ The full dual problem will then be formally introduced in section 4.

\footnotetext{
${ }^{1}$ On enforcement issues with common property resources see, for instance, Ostrom (1990) and Stevenson (1991).

${ }^{2}$ See Hotte (2005) for a model of resource use with imperfect input exclusion only.
} 


\subsection{The players and their actions}

There are $m+1$ individuals: one resource manager and $m$ thieves. The manager chooses an input level $X \geq 0$. Thief $k$ chooses theft effort $z_{k} \geq 0$, $k \in\{1,2, \ldots, m\}$. The total theft effort is denoted $Z=\sum_{k=1}^{m} z_{k}$.

\subsection{The payoffs}

The thieves Let $s$ denote the total share of output appropriated by all thieves combined. The total theft effort being equal to $Z$, this share depends positively on total theft effort according to the following theft function:

$$
s=s(Z), s \in[0,1], s_{Z}>0, s_{Z Z}<0, s(0)=0, \lim _{Z \rightarrow \infty} s(Z)=1 .
$$

Decreasing returns to theft may be justified by the fact that some outputs are easier to steal than others. In the case of grazing land for instance, thieves may easily steal first the stray cattle far away from the rancher's home, and then need more time to get to the other cattle. Figuratively speaking, thieves will pick the low-lying fruits first.

Given $X$, the thieves' total booty is thus $s(Z) p f(X)$. Under the assumption that thieves are identical in terms of the productivity of their efforts, we posit that a thief collects a share of the total booty which corresponds to the proportion of his effort with respect to the total effort; that is, the booty for thief $k$ is given by $y_{k}^{s}=\left(z_{k} / Z\right) s(Z) p f(X)$. (Superscript $s$ refers to the activity of stealing.) For further analysis, it will be convenient to introduce function $\bar{s}(Z)$ as the share stolen per unit theft effort; that is, $\bar{s}(Z) \equiv s(Z) / Z$, where $\bar{s}^{\prime}(Z)<0$ due to decreasing returns.

Each thief is assumed to have a constant unit opportunity cost of theft effort equal to $w$. Moreover, the presence of a local justice system, norms, or retaliation possibilities, is such that each thief expects to be caught with exogenous probability $\theta \in[0,1]$. If thief $k$ is caught, his booty is simply confiscated and returned to the community as a whole. No other penalty is exacted. We therefore have that for given input level $X$ and effort levels of the other $m-1$ thieves denoted $Z_{-k} \equiv \sum_{\substack{j=1 \\ j \neq k}}^{m} z_{j}$, the expected payoff for thief $k$ is given by

$$
\pi_{k}^{s}=z_{k} \bar{s}\left(z_{k}+Z_{-k}\right)(1-\theta) p f(X)-w z_{k} .
$$


The manager The manager's unit input cost is assumed constant and equal to $c$. For a given total theft effort level $Z$, he loses a share $s(Z)$ of his output, so that his gain is given by

$$
\pi^{m}=(1-s(Z)) p f(X)-c X .
$$

\subsection{The sequence of decisions}

We assume that the manager acts as a leader by first choosing input quantity $X$. Thieves then choose their theft efforts after having observed output level $y$. Those theft efforts are however chosen simultaneously between thieves and non-cooperatively in Nash fashion. This means that each thief must choose his effort level before knowing what other thieves' decisions are. Those decisions may however be correctly anticipated as each is perfectly informed about the presence of the other thieves and their problem set.

\subsection{The theft equilibrium}

We now derive the equilibrium choices for each individual. We begin with the theft equilibrium since it is the last stage. We subsequently move up to the choice of the manager who may anticipate the thieves' reactions.

\subsubsection{The theft stage}

The individual reaction functions are obtained by solving for the following problem, for fixed $X$ and $Z_{-k}$ :

$$
\max _{z_{k}} \pi_{k}^{s}=z_{k} \bar{s}\left(z_{k}+Z_{-k}\right)(1-\theta) p f(X)-w z_{k} .
$$

The first-order condition yields the following set of reaction functions:

$$
\frac{\partial \pi_{k}^{s}}{\partial z_{k}}=\left[\bar{s}(Z)+z_{k} \bar{s}^{\prime}(Z)\right](1-\theta) p f(X)-w=0, \forall k \in\{1, \ldots, m\} .
$$

The first term between square brackets represents the (marginal) benefit from a unit increase in theft effort. This is equal to the share of stolen output per unit theft effort multiplied by the total output value and adjusted for the probability of being caught. The second term between square brackets is negative and accounts for the diminishing returns from theft efforts. 
Given that thieves are all identical, we characterize the symmetrical Nash equilibrium in which $z_{1}^{e}=z_{2}^{e}=\ldots=z_{m}^{e} \equiv z^{e}$. The total equilibrium theft effort is thus $Z^{e}=m z^{e}$ and is given by the following condition, which insures that each thief's choice of effort falls on his reaction function:

$$
\left[\bar{s}\left(Z^{e}\right)+\frac{Z^{e}}{m} \bar{s}^{\prime}(Z)\right](1-\theta) p f(X)=w .
$$

Through implicit differentiation of (5), one obtains that $Z^{e}$ is increasing in $X$, which leads us to assert the following:

Proposition 1 Output theft can be reduced through a reduction in the input level.

For analytical convenience, we shall approximate a situation with a large number of thieves by considering the case where $m \rightarrow \infty$, in which case equilibrium (5) becomes $^{3}$

$$
\bar{s}\left(Z^{e}\right)(1-\theta) p f(X)=w .
$$

Proof: Through implicit differentiation, (5) gives $\partial Z^{e} / \partial m>0$. Since $\lim _{Z \rightarrow \infty} s(Z)=1$, we have $\lim _{Z \rightarrow \infty} \bar{s}(Z)=0$. This implies that $\lim _{m \rightarrow \infty} Z^{e}<$ $\infty$, lest condition (5) be violated. Consequently $\lim _{m \rightarrow \infty} Z^{e} / m=0$ and we obtain (6).

Note that consistently with proposition 1, expression (6) implies the following:

$$
\frac{\partial Z^{e}}{\partial X}=\frac{s(Z)}{\bar{s}(Z)-s^{\prime}(Z)} \frac{f^{\prime}(X)}{f(X)}>0,
$$

It can similarly be verified that the supply of theft effort decreases with its opportunity cost $w$ and the enforcement level $\theta$, and increases with the resource price $p$. Assuming further that $\lim _{Z \rightarrow 0} \bar{s}(Z)<\infty$, we have that with sufficiently large $w$ or $\theta$, or with low enough output $X$, theft activities can be completely deterred if the following inequality holds:

$$
\bar{s}(0) p f(X) \leq \frac{w}{1-\theta} .
$$

\footnotetext{
${ }^{3}$ For additional insight, it may be interesting to consider the case of a finite number of thieves. There is no reason to believe, however, that this would alter the fundamental qualitative results of this paper. Since this would significantly increase the complexity of the analysis, we leave this for future work.
} 
In the ensuing analysis, it will be convenient to refer to term $\bar{s}(X) p f(X)$ as the ex-enforcement return to theft and the right-hand side term as the enforcement-adjusted opportunity cost of theft efforts. According to (6), $\theta>0$ implies that the unit return to theft incorporates a risk premium. Let us now turn to the decision of the resource manager.

\subsubsection{The input decision stage}

The manager's problem is to choose the input level $X$ while anticipating its effect on the total theft effort $Z^{e}$ implicitly determined by equality (6). This problem can be expressed as follows:

$$
\begin{array}{rc}
\max _{X, Z^{e}} \pi^{m}= & \left(1-s\left(Z^{e}\right)\right) p f(X)-c X, \\
\text { s.t. } & \bar{s}\left(Z^{e}\right)(1-\theta) p f(X) \leq w, \\
Z^{e} \geq 0,
\end{array}
$$

along with the complementary slackness condition. The first-order condition for an interior solution is

$$
\frac{\partial \pi^{m}}{\partial X}=\left(1-s\left(Z^{e}\right)\right) p f^{\prime}\left(X^{s}\right)-s^{\prime}\left(Z^{e}\right) \frac{\partial Z^{e}}{\partial X} p f\left(X^{s}\right)-c=0,
$$

where $\partial Z^{e} / \partial X$ is given by (7) and $X^{s}$ denotes the profit maximizing choice of the manager. The first term in the derivative denotes the benefit from a marginal increase in $X$, which is equal to the additional output produced adjusted for the fact that only share $1-s\left(Z^{e}\right)$ will accrue to the manager. The middle term is a cost which accounts for the fact that an input increase tends to attract more theft effort and thus increases the stolen share by amount $s^{\prime}\left(Z^{e}\right)\left(\partial Z^{e} / \partial X\right)$. The third term is just the direct marginal input cost.

First-order condition (12) indicates that in an interior solution, theft acts as an ad-valorem tax on output. Interestingly, however, the magnitude of the tax is endogenous as it is set by the manager himself when he takes into account the effect of $X$ on $Z^{e}$. Hence the following proposition:

Proposition 2 The presence of output theft acts as an ad-valorem output tax imposed on the resource manager, the magnitude of which is endogenously set by the resource manager herself. 
In the case of a corner solution, the following conditions hold at $Z^{e}=0$ and $X^{s}<X^{*}$ :

$$
\begin{aligned}
& \frac{\partial \pi^{m}}{\partial X}=p f^{\prime}\left(X^{s}\right)-s^{\prime}\left(Z^{e}\right) \frac{\partial Z^{e}}{\partial X} p f\left(X^{s}\right)-c \leq 0, \\
& \bar{s}(0)(1-\theta) p f\left(X^{s}\right)=w .
\end{aligned}
$$

This condition corresponds to a situation where the resource manager produces at the maximum level before which thieves become interested in stealing the output. Though there is no theft in this equilibrium, the theft problem is still present given that it affects the choice of $X$.

Finally, one may also envisage the possibility that the following inequality holds:

$$
\bar{s}(0)(1-\theta) p f\left(X^{*}\right) \leq w .
$$

In this case, the manager can produce at the rent maximizing level without worrying about theft at all. This may be made possible by a high enforcement level $\theta$ and would correspond to the implicit assumption of immediate output marketing.

Note finally that through rearrangement of interior condition (12), we have the following inequality regarding the equilibrium marginal product on the resource:

$$
p f^{\prime}\left(X^{s}\right)=\frac{c+s^{\prime}\left(Z^{e}\right) \frac{\partial Z^{e}}{\partial X} p f\left(X^{s}\right)}{1-s\left(Z^{e}\right)}>c .
$$

Since $f^{\prime \prime}<0$, this implies that the resource manager chooses an input quantity that is lower than the efficient one as defined by (1); that is, $X^{s}<X^{*}$. Inequality (16) makes clear that this under-use result is brought about by two effects: One is the tax effect due to term $\left(1-s\left(Z^{e}\right)\right)$. The other is due to term $s^{\prime}\left(Z^{e}\right)\left(\partial Z^{e} / \partial X\right)$ which may be termed a deterrence effect since it aims to lower $s(Z)$ through an input reduction. In the case of corner solution (13), only the deterrence effect is present. The above results are summarized by the following proposition:

Proposition 3 The possibility of output theft causes the resource to be underused. In an interior solution, underuse is due to a combination of both a tax and a deterrence effect. In a corner solution, underuse results from just a deterrence effect. 
The interior solution case is represented by point $B$ in figure 2 , where $\Delta(Z)$ denotes the theft effort increase effect in expression (12); that is, $\Delta(Z) \equiv s^{\prime}\left(Z^{e}\right)\left(\partial Z^{e} / \partial X\right) p f\left(X^{s}\right)$. The (classical) efficient use level in the absence of theft is located at point $C l$.

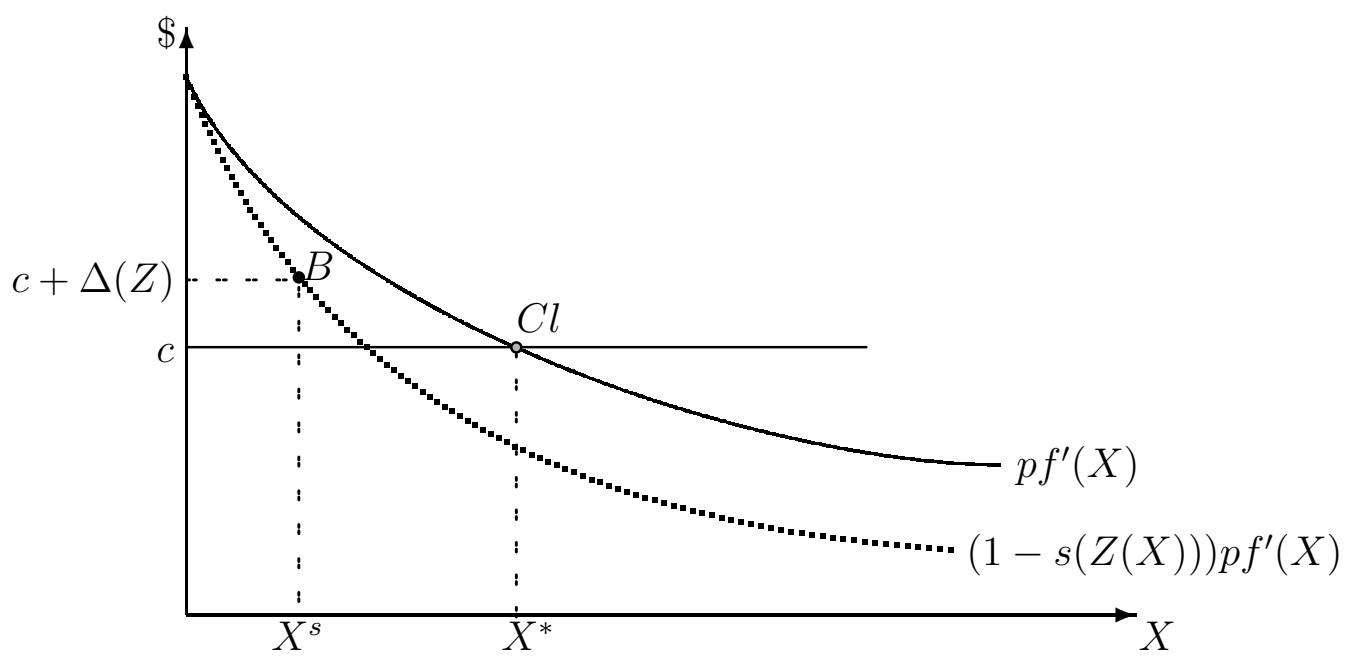

Figure 2: Resource underuse under contestable outputs

\section{The dual problem of exclusion}

In this section, we consider a setting with a generally weak state presence in the sense that the resource manager must face a dual problem of exclusion, that is, over both inputs and outputs.

\subsection{The agents and their actions}

Recall that in the introduction to section 3, we referred to unauthorized use of the resource as trespass. So in addition to a resource manager and $m$ thieves, we now have $n$ trespassers. ${ }^{4}$ There are thus $m+n+1$ players. The manager and trespasser $i$ each choose their input quantities to exploit the

\footnotetext{
${ }^{4}$ The trespass part of the model is based on Hotte (2005).
} 
resource, denoted $x^{m}$ and $x_{i}^{t}$ respectively, $i \in\{1,2, \ldots, n\}$. The total input level is now given by

$$
X=x^{m}+\sum_{i=1}^{n} x_{i}^{t}
$$

As before, thief $k$ chooses theft effort $z_{k} \geq 0, k \in\{1,2, \ldots, m\}$, for a total theft effort $Z=\sum_{k=1}^{m} z_{k}$.

\subsection{The payoffs}

The thieves The thieves' payoffs are identical to those of section 3.2. Note that thieves do not differentiate between the outputs of the manager and those of the various trespassers.

The trespassers Trespassers are all identically productive in terms of their input efforts. This productivity is also assumed identical to that of the resource manager. The average product of each input is thus the same for all and is represented by the following function for analytical convenience: $\bar{f}(X) \equiv f(X) / X$, where $\bar{f}^{\prime}(X)<0$ due to decreasing returns. The output harvested by trespasser $i$ 's input is thus given by $x_{i}^{t} \bar{f}(X)$.

Given thieves' total effort $Z$, each trespasser expects to lose a share $s(Z)$ from his own output. Moreover, each trespasser expects to be caught with probability $\lambda \in[0,1]$, in which case his or her output is simply confiscated and returned to the community as a whole. No other penalty is exacted. Assuming a constant input unit cost $c$, trespasser j's expected payoff is given by the following:

$$
\pi_{j}^{t}=x_{j}^{t}(1-\lambda)(1-s(Z)) p \bar{f}(X)-c x_{j}^{t} \text { where } X=x^{m}+\sum_{i=1}^{n} x_{i}^{t} .
$$

The resource manager The manager chooses input quantity $x^{m}$ at constant unit cost $c$ and average product $\bar{f}(X)$. This yields the following gain:

$$
\pi^{m}=(1-s(Z)) p \bar{f}(X) x^{m}-c x^{m} \text { where } X=x^{m}+\sum_{i=1}^{n} x_{i}^{t} .
$$




\subsection{The sequence of decisions}

The sequence of decisions follows three stages:

1. The manager chooses $x^{m}$ first.

2. Each trespasser $i$ then chooses his or her input level $x_{i}^{t}, i \in\{1,2, \ldots, n\}$, after having observed the manager's input choice $x^{m}$. The trespassers' decisions are however taken simultaneously and non-cooperatively, in Nash fashion.

3. As in section 3, each thief $k$ observes the total output level $y=f(X)$ and decides on a level of theft effort $z_{k}, k \in\{1,2, \ldots, m\}$. Thieves' decisions are taken simultaneously and non-cooperatively, in Nash fashion.

\subsection{The dual equilibrium}

We now derive the equilibrium choices of each agent. We begin with the theft equilibrium since it is the last stage. We then move up to the trespass equilibrium, in which trespassers can anticipate the thieves' reactions. The choice of the manager is considered last, as she can anticipate both the trespassers' and the thieves' reactions. Throughout the analysis, all agents take as given the probabilities of catching either a thief or a trespasser, denoted $\theta$ and $\lambda$ respectively, which act as proxies for the weakness of property rights over output appropriation and input uses respectively, or the state's presence.

\subsubsection{The third stage: Theft}

The thieves' equilibrium is identical to that of section 3.4.1, the sole difference being that the total input $X$ is now given by expression (17). For simplicity, we still assume that the number of thieves is large enough that the theft equilibrium can be approximated by equilibrium condition (6).

\subsubsection{The second stage: Trespass}

We now turn to the second stage, in which $n$ trespassers simultaneously choose their input quantities after having observed $x^{m}$ and while anticipating the thieves' reaction as per equation (6). The problem of trespasser $j$ is 
expressed as follows:

$$
\begin{aligned}
& \max _{x_{j}^{t}} \pi_{j}^{t}=x_{j}^{t}(1-s(Z))(1-\lambda) p \bar{f}(X)-c x_{j}^{t}, \\
& \text { s.t. } \bar{s}(Z)(1-\theta) p f(X)=w, \\
& \text { and } X=x^{m}+\sum_{i=1}^{n} x_{i}^{t} .
\end{aligned}
$$

Assuming an interior solution, trespasser j's reaction function is characterized by the following first-order condition:

$\frac{\partial \pi_{j}}{\partial x_{j}^{t}}=(1-\lambda) p\left\{(1-s(Z)) \bar{f}(X)+x_{j}^{t}\left[(1-s(Z)) \bar{f}^{\prime}(X)-s^{\prime}(Z) \bar{f}(X) \frac{\partial Z}{\partial X}\right]\right\}-c=0$.

This condition states that when adding a (marginal) unit input to the resource, a trespasser has to weigh the benefit that the average product confers to additional revenues, against its costs, composed of the induced drop in average productivity, the induced increase in theft efforts, and the direct cost of an input. In this calculation, only the direct cost is known with certainty; the other costs and benefits are weighed by the probability of not being caught. Moreover, the added revenue and negative productivity effects only matter for the share that is not lost to theft. And finally, since trespasser $j$ is only concerned about how the negative productivity and increased theft effects affects his own profit, the term between square brackets is weighed by $x_{j}^{t}$.

One notes that in the presence of theft, the fact that trespassers act as non-cooperative users generates two types of negative externalities. Indeed, if all $n+1$ resource users were to behave cooperatively and maximize total rents while dealing with the problem of theft, the term between square brackets would be multiplied by $X$ instead of $x_{j}^{t}$ only. One externality is due to the well-known negative product effect $\bar{f}^{\prime}(X)$. But we now have the additional increased theft effect $s^{\prime}(Z) \partial Z / \partial X$. This is due to the fact that an increase in resource output causes an increase in the theft payoff which results in more theft losses for all users. Hence the following proposition:

Proposition 4 In the presence of theft, imperfect exclusion over input use leads to two types of negative externalities between users: A negative product effect and an increased theft effect. 
We characterize the symmetric Nash equilibrium by letting $x_{1}^{t e}=x_{2}^{t e}=$ $\ldots=x_{n}^{t e} \equiv x^{t e}$. The total trespassing effort is thus $=n x^{t e}$. Inserting this into reaction function (23), the Nash equilibrium total trespass effort for given $x^{m}$ is characterized by the following:

$$
(1-\lambda) p\left\{(1-s(Z)) \bar{f}(X)+\frac{x^{t e}}{n}\left[(1-s(Z)) \bar{f}^{\prime}(X)-s^{\prime}(Z) \bar{f}(X) \frac{\partial Z}{\partial X}\right]\right\}-c=0
$$

where $X=x^{m}+n x^{t e}$. Approximating a sitation with a large number of trespassers with the limiting case where $n \rightarrow \infty$, condition $(24)$ becomes $^{5}$

$$
(1-\lambda)(1-s(Z)) p \bar{f}\left(x^{m}+n x^{t e}\right)=c .
$$

Not surprisingly, trespassers' expected rents are exhausted when there is an arbitrarily large number of them. This outcome is analogous to that of an open access regime, with the difference that the average gain must be adjusted for the probability of being caught and punished, as well as the share lost to theft. This difference is not innocuous since with $\lambda>0$, the average product exceeds the true average $\operatorname{cost} c$ in this equilibrium and thus the resource may still generate net positive rents to the manager, as will be discussed in detail below. ${ }^{6}$

Equalities (6) and (25) together form a system which determines both the (interior) theft and trespass levels for a given input choice $x^{m}$. Through implicit differentiation, we obtain the following effect of an increase in the manager's input level:

$$
\frac{\partial\left(n x^{t e}\right)}{\partial x^{m}}=-1<0 \text { and } \frac{\partial\left(Z^{e}\right)}{\partial x^{m}}=0
$$

Hence the following proposition:

Proposition 5 Provided that $Z^{e}>0$ and $n x^{t e}>0$, trespassing can be deterred through an increase in the exploitation level, while the theft effort level remains unaffected.

This proposition calls for a few remarks. Firstly, according to (26), not only does an increase in the manager's input level deter trespass, but it does so

\footnotetext{
${ }^{5}$ The proof is similar to that of expression (6) and is omitted. See also Hotte (2005).

${ }^{6}$ Put differently, $\lambda>0$ implies an equilibrium with a risk a premium for trespassers.
} 
at a one-to-one ratio, thus leaving the output unchanged. This explains why the theft effort remains unaffected. Given that the manager can anticipate those reactions, it will impact her exploitation decisions. Secondly, it should be noted that those results are obtained under the approximations of large numbers of both thieves and trespassers. As will become clear below, those assumptions have the advantage of greatly simplifying the analysis while preserving the qualitative nature of the dual exclusion problem facing the resource manager.

\subsubsection{The first stage: The manager}

For simplicity, we consider interior theft cases only. In the case of an interior solution for trespass also, the manager's problem is expressed as follows:

$$
\begin{array}{cc}
\max _{x^{m}, x^{t e}, Z^{e}} \pi^{m}= & (1-s(Z)) p \bar{f}(X) x^{m}-c x^{m}, \\
\text { s.t. } \quad & (1-s(Z)) p \bar{f}(X)=\frac{c}{1-\lambda}, \quad \text { for } n x^{t e}>0, \\
& \bar{s}(Z)(1-\theta) p f(X)=w, \\
X=x^{m}+n x^{t e} .
\end{array}
$$

According to constraint (28), a positive trespass level $n x^{\text {te }}>0$ implies that $(1-s(Z)) p \bar{f}(X)$ is constant in $x^{m}$ and larger than $c$. The marginal return to $x^{m}$ is therefore larger than its marginal cost. As a result, the manager will choose to increase $x^{m}$ up until $n x^{t e}$ becomes zero; that is, up until trespassing is completely deterred, at which point equality (28) can be expressed as $(1-s(Z)) p \bar{f}\left(x^{m}\right)=c /(1-\lambda)$ and the manager's problem can be restated as follows:

$$
\begin{array}{rll}
\max _{x^{m}, Z^{e}} \pi^{m}= & (1-s(Z)) p f\left(x^{m}\right)-c x^{m}, & \\
\text { s.t. } \quad & (1-s(Z)) p \bar{f}\left(x^{m}\right) \leq \frac{c}{1-\lambda} & \text { [trespass constraint] } \\
& \bar{s}(Z)(1-\theta) p f\left(x^{m}\right)=w \quad \text { [theft constraint] }
\end{array}
$$

The inequality in the trespass constraint accounts for the possibility that for some given $x^{m}$, trespassers may receive a strictly negative return from any amount of their effort, however small.

The manager's optimal choice must respect the following inequality:

$$
\frac{\partial \pi^{m}}{\partial x^{m}}=(1-s(Z)) p f^{\prime}\left(x^{m}\right)-s^{\prime}(Z) \frac{\partial Z}{\partial x^{m}} p f\left(x^{m}\right)-c \leq 0 .
$$


The inequality in (34) accounts for the fact that $x^{m}$ may be determined by the trespass constraint (32) as a strict equality. If (34) is respected with strict equality, then trespass is not affecting equilibrium decisions. This could be because exclusion enforcement against trespassers is high enough ( $\lambda$ is high) or because theft is so important that trespassers are completely deterred, or a combination of both. Conversely, if the trespass constraint binds in equilibrium while (34) is respected with strict inequality, then trespass does affect input decisions.

Note that the problem contains two endogenous variables, $x^{m}$ and $Z$, and is thus fully determined by two equalities: (33) and either of (34) or (32). Consequently, two types of equilibria emerge which depend on whether the trespass constraint is binding or not. They are characterized by the following conditions:

Non-binding trespass If constraint (32) is not binding, the equilibrium is fully described by (34) being respected with equality and (33).

Binding trespass If constraint (32) is binding, the equilibrium is fully described by (32) being respected with equality and (33).

As will be seen in the next section, which of the two equilibrium type holds in practice leads to different predictions regarding resource use.

\section{Characterization of the equilibrium types}

An equilibrium with a non-binding trespass constraint is referred to as a theft equilibrium while one with a binding trespass constraint is called trespasstheft equilibrium. In the proposed partial equilibrium setting, which of the two equilibria holds will depend on the given prices $w, c$ and $p$, as well as by the given enforcement levels $\theta$ and $\lambda$. For simplicity, it will be convenient to compare equilibria by assuming exogenous changes in the trespass enforcement level $\lambda$ only. We begin by assuming that a theft equilibrium is obtained at a "high" value $\lambda_{0}$.

\subsection{The theft equilibrium}

In the theft equilibrium, $\lambda_{0}$ is such that equation (34) is respected with equality and the equilibrium is the same as that of equation (16) in section 3.4 and illustrated in figure 2. This result is represented again in figure 3 
where trespass payoff curve $(1-s(Z)) p \bar{f}(X)$ has been added. The figure underscores the fact that even though the trespass payoff increases as input use is made smaller than $X^{*}$, the theft equilibrium point $B$ yields a trespass payoff which is still smaller than its detection adjusted opportunity cost $c /\left(1-\lambda_{0}\right)$ (see point $C$ ). It is interesting to note that if, for some reason, trespassers were not subject to theft as the manager is, then the trespass constraint would become binding as the trespass payoff without theft at $x_{0}^{m}$ exceeds $c /\left(1-\lambda_{0}\right)$ (see point $\left.D_{0}\right)$. One may therefore conclude that the manager benefits from the fact that potential trespassers also suffer from the theft problem.

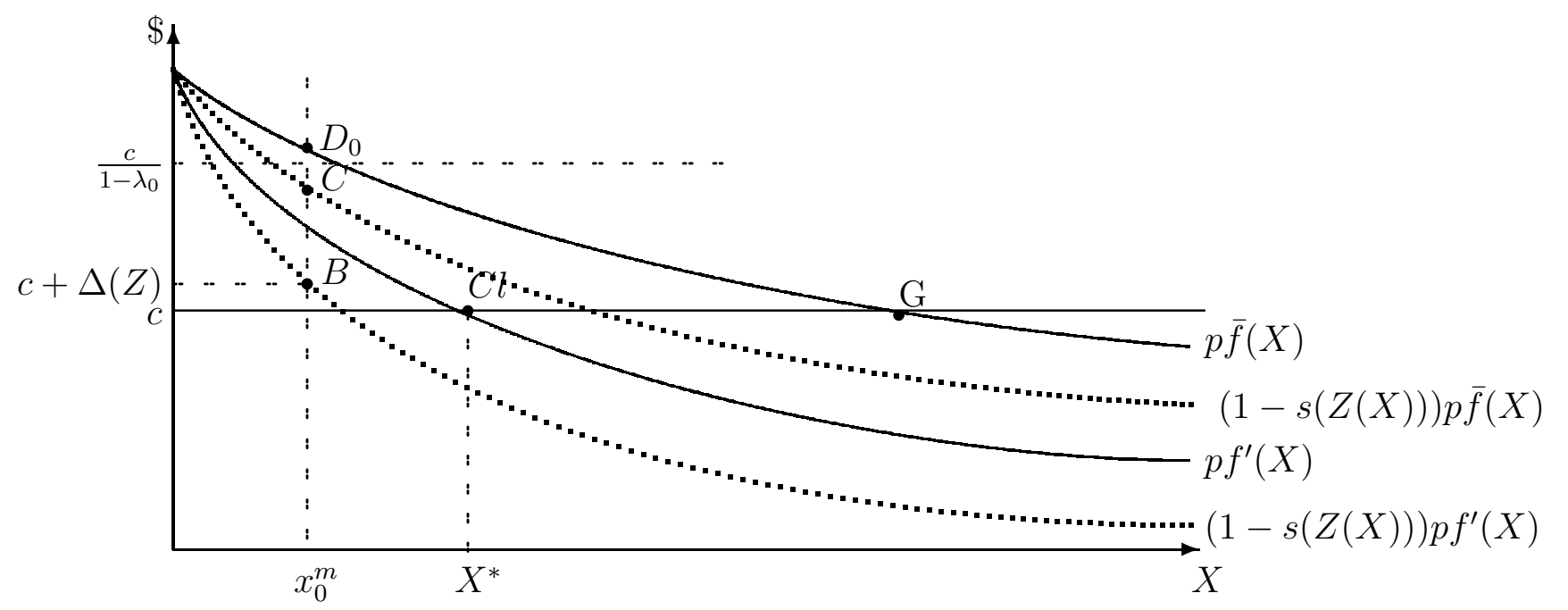

Figure 3: Resource underuse with theft and non-binding trespass

In summary, the conclusions of proposition 3 still hold when the trespass constraint is not binding. We now consider the case of a lower trespass enforcement level $\lambda_{1}<\lambda_{0}$.

\subsection{The trespass-theft equilibrium}

Suppose that the trespass enforcement level $\lambda_{1}$ is such that at $x_{0}^{m}$, the enforcement adjusted opportunity cost of trespass $c /\left(1-\lambda_{1}\right)$ is now lower than the trespass payoff $\left(1-s\left(Z\left(x_{0}^{m}\right)\right)\right) p \bar{f}\left(x_{0}^{m}\right)$, as illustrated by point $C$ in figure 
4. The trespass constraint is now binding. Consequently, in order to deter trespassers, the manager opts to raise input quantities to level $x_{1}^{m}$, where both equalities (33) and (32) are respected, while (34) is a strict inequality.

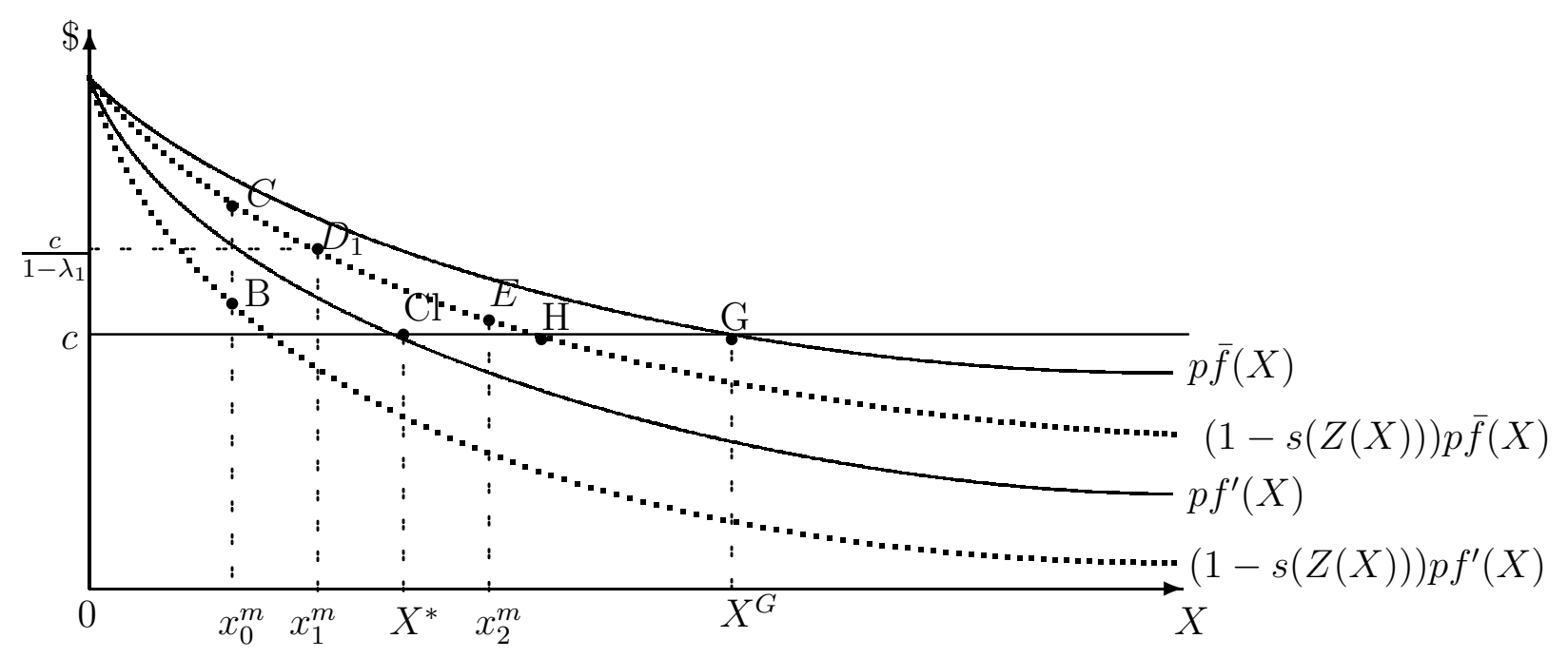

Figure 4: Resource under- and over-use under a dual property right problem

With trespass enforcement level $\lambda_{1}$, although the resource is still being underused at input quantity $x_{1}^{m}$, the problem is not so severe as it was with $\lambda_{0}$. More rents are therefore being generated on the resource. Now though this may look like an efficiency improvement on the previous situation, a closer analysis reveals otherwise.

Note first that the manager chooses $x_{1}^{m}$ over $x_{0}^{m}$ because he is now constrained to do so by the binding trespass constraint. The introduction of an additional constraint suggests that the manager cannot be doing better at exploitation level $x_{1}^{m}$ and this is in fact the case. Notice that with a nonbinding trespass constraint, we have $\partial \pi^{m} / \partial x^{m}<0$ for all $x^{m}>0$. In order to deter trespassers, the manager is therefore hiring additional inputs whose theft adjusted marginal product is strictly lower than their cost. (Recall that he does so because trespassers would in any case bring the exploitation level to $x_{1}^{m}$.) As a result, the manager's realized rents must be strictly lower at $x_{1}^{m}$ than $x_{0}^{m}$. 
We therefore have that the resource produces more rents with the lower trespass enforcement level while the manager receives less rents. The thieves are therefore picking up the difference. This does not, however, imply that they are made better off in the process. Indeed, the additional resource output induces thieves to increase their theft effort by so much that the larger booty is entirely dissipated by the costs of those efforts. The upshot is that in order to determine whether there is an overall efficiency gain, it must be the case that the resource manager's loss be smaller than the cost savings originating from the lower trespass enforcement level $\lambda_{1}$.

We therefore have that whenever trespass is binding, weaker trespass enforcement leads to the adoption of higher input quantities by the manager. In figure 4 , it can be readily seen that further decreases in the value of $\lambda$ lead to new equilibria to the right of point $D_{1}$ along curve $(1-s(Z(X))) p \bar{f}(X)$. With a low enough value of $\lambda$, we may thus encounter an equilibrium in which the resource is being overused. This possibility is illustrated by point $E$ in figure 4 , where the equilibrium input level $x_{2}^{m}$ exceeds $X^{*}$. The following proposition summarizes the foregoing observations:

Proposition 6 In the presence of theft, trespass tends to mitigate the problem of resource underuse and may even lead to overuse. The manager's rents strictly decrease while thieves are no better off. Whether there is an efficiency gain will depend on the magnitude of the cost savings from lower trespass enforcement.

This proposition introduces an indeterminacy in the theoretical prediction regarding natural resource use in settings characterized by generally weak property right enforcement. Indeed, in such cases, trespassing and theft are likely to be both significant problems for the resource manager. Whether this leads the resource to be over- or under-exploited in equilibrium will depend on the parameters of the problem, and those are ultimately determined by the specific case at hand.

A corollary to proposition 6 is that the presence of theft may mitigate the problem of resource overuse. To see why, suppose a situation of open access à la Gordon (1954) with parameter values $\theta=1$ and $\lambda=0$ as discussed in section 2. The equilibrium is then at point $G$ in figure 4 , where $p \bar{f}\left(X^{G}\right)=c$. Introducing theft shifts the equilibrium exploitation level back, say to point H. Hence the following corollary: 
Corollary 7 The presence of theft tends to mitigate the problem of resource overuse.

In the light of those results, the next section is devoted to a reinterpretation of the cases discussed in section 2 . We do so by proposing some enforcement levels $\lambda$ and $\theta$ which we consider to be reasonable approximations of each specific case.

\section{A fresh look at the evidence}

\subsection{The Gold Rush and the whalers}

We argued in section 2 that both the Gold Rush and the whaling industry could be represented by an open access to inputs $(\lambda=0)$ and an imperfect output appropriation $(0<\theta<1)$. Representing the Gold Rush equilibrium exploitation level by $X^{G R}$, it is then characterized by the following conditions:

$$
\begin{gathered}
(1-s(Z)) p \bar{f}\left(X^{G R}\right)=c, \\
\bar{s}(Z)(1-\theta) p f\left(X^{G R}\right)=w .
\end{gathered}
$$

A comparison with open access and immediate marketing condition $p \bar{f}\left(X^{G}\right)=$ $c$, this yields $X^{G R}<X^{G}$. We therefore conclude that if claims to land containing gold had been easy to secure, exploration efforts may have been even higher.

Under the same mechanism, one may conjecture that in the case of the whaling industry, the adoption of a norm of capture had the effective impact of increasing $\theta$. In accordance with corollary 7 , whalers may then have found it beneficial to increase the whaling efforts, an effect which, paradoxically, may have contributed to the disappearance of the industry through a depletion of the resource.

\subsection{Cattle theft in the open range}

In figure 1, the case of the open range in the American West was represented by intermediate values of both $\theta$ and $\lambda$. According to our analysis, whether the grassland was actually over- or under-stocked is consequently impossible to say without additional information. Yet, as mentioned in section 2, researchers on the subject appear to have adopted the view that there was over-stocking. We suspect that this position may be due to the habit of 
equating weak property rights with overuse. What is undisputable is that ranchers did face a serious dual enforcement problem due to a weak state presence. Based on this alone, one cannot be sure whether the land was being over-or under-stocked, as the equilibrium can be represented by either of points $E$ or $D_{1}$ in figure 4 .

The problem of theft faced by common pasture cattlemen in Africa and farmers in Zimbabwe, on the other hand, reports clearly an underuse of the pasture. This is illustrated in figure 5 by the curve $(1-s(Z(X))) p \bar{f}(X)$ which is assumed to drop sharply with $X$ and yields an equilibrium at $X^{C P A}$.

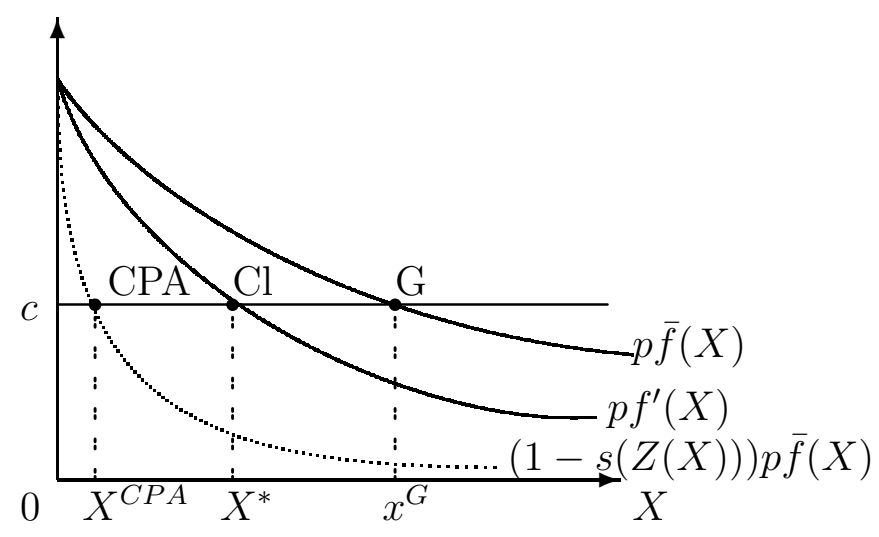

Figure 5: Severe resource underuse under open access and theft

\subsection{Farm theft}

As discussed in section 2, urban agriculture is often severely affected by the problem of theft. Indeed, not only is protection difficult to achieve on urban plots, but the opportunity cost of thieves can be quite low due to their natural proximity. It is well established in the crime literature that property theft is a crime of opportunity as evidenced by the fact that proximity between victims and criminals is an important determinant. In our model, this implies both a low theft enforcement parameter $\theta$ and opportunity cost of theft efforts $w$. From (6), one can readily verify that a low $\theta$ value combined with a low $w$ implies that the ex-enforcement theft payoff $\bar{s}(Z) p f(X)$ must remain low. This corresponds to either little output being produced or a large amount of 
theft effort is necessary to drive down $\bar{s}(Z)$. But with a large theft effort, $s(Z)$ becomes arbitrarily close to 1 which, once inserted into condition (16), leads to an equilibrium marginal product of the resource much in excess of its marginal cost $c$. Either way, we end up with severe resource underuse.

In the cases of urban home farming and rural theft, if we assume that $\theta^{U H F}>\theta^{R T}$ and given that $\lambda \approx 1$, we would have $X^{U L F}<X^{R T}<X^{U H F}<$ $X^{*}$.

\subsection{Inshore fishery}

This case is illustrated in figure 1 by $\theta=1$ and $0<\lambda<1$. We thus have $Z=0$ and $s(Z)=0$ and the following inequality holds:

$$
p \bar{f}\left(X^{*}\right)>\frac{c}{1-\lambda} .
$$

Parameter $\lambda$ is therefore not high enough to completely deter trespassing at efficient input level $X^{*}$. The manager will consequently increase the input use at $X^{I F}>X^{*}$ in order to bring down the average product to the point where trespassers are completely deterred, that is,

$$
p \bar{f}\left(X^{I F}\right)=\frac{c}{1-\lambda} .
$$

In the presence of partial input exclusion enforcement, we therefore have $X^{*}<X^{I F}<X^{G}$. Such inshore fisheries are overexploited but not so much as to completely dissipate the rents.

\section{Conclusion}

Our analysis started out with the observation that in the Gordon (1954) model, although resource users could not be excluded from exploiting a resource, they enjoyed full property rights over the fruits of their efforts. Since this results in resource overuse, weak property have tended to be equated with resource overuse. This representation of weak property rights over natural resources has essentially become the norm over the years.

In this paper, we presented evidence to the effect that weak property rights can also often take the form of output appropriation problems, or theft. This will typically be the case under a weak state presence. A situation in which problems of both input exclusion and output appropriation are 
simultaneously present was referred to as a dual enforcement problem. A theoretical model was then proposed to gain insight into the nature of the the dual problem. As a principal result, we showed that each property right problem tends to pull input use in opposite directions: A lower enforcement of input exclusion tends to increase input use while a lower enforcement of output appropriation tends to lower input use. This has led us to conclude that when property rights are generally weak, one cannot say whether a natural resource will be over- or under-exploited in equilibrium.

There are many directions in which this work could be extended. Obvious ones include the introduction of explicit resource dynamics or endogenous enforcement of property rights. Another one would be a normative analysis of the timing of public enforcement measures, that is, given that it is costly to increase $\theta$ and $\lambda$, which of the two should the state concentrate on first? Relatedly, both Ellickson (1991) and Umbeck (1981) report on efforts by local communities to solve the problem of output appropriation while seemingly ignoring input access issues. The present model may be used as a basis for a positive analysis of this behavior. Finally, we hope that the analysis will inspire empirical work with regards to natural resource use in developing economies.

\section{References}

[1] Agricultural theft: Rich pickings. SPORE, 139:11, 2009.

[2] James H. Acheson. The Lobster gangs of Maine. University Press of New England, 1988.

[3] Terry L. Anderson and P. J. Hill. The evolution of property rights: A study of the american west. The Journal of Law and Economics, 18:163-179, April 1975.

[4] Erik Bryld. Potentials, problems, and policy implications for urban agriculture in developing countries. Agriculture and Human Values, 20:7986, 2003.

[5] Robert C. Ellickson. Order Without Law: How Neighbors Settle Diputes. Harvard Universitry Press, 1991.

[6] Frank Ellis and James Sumberg. Food production, urban areas and policy responses. World Development, 26:213-25, 1998. 
[7] Marcel Fafchamps and Bart Minten. Crime, transitory poverty, and isolation: Evidence from madagascar. Economic Development and Cultural Change, 54:579-603, 2006.

[8] Gerard Gaudet, Michel Moreaux, and Stephen W. Salant. Private storage of common property. Journal of Environmental Economics and Management, 43(2):280-302, March 2002.

[9] H. Scott Gordon. The economic theory of a common-property resource: The fishery. Journal of Political Economy, VXII:124-142, April 1954.

[10] Louis Hotte. Natural-resource exploitation with costly enforcement of property rights. Oxford Economic Papers, 57(3):497-521, 2005.

[11] Alice Mboganie-Mwangi and Dick Foeken. Urban agriculture, food security and nutrition in low income areas of the city of nairobi, kenya. Afncan Urban Quarterly, 11:170-79, 1996.

[12] Stephen Mbogo. Pastoral shoot-outs. Technical report, Toward Freedom, 2005.

[13] Randy McFerrin and Douglas Wills. High noon on the western range: A property rights analysis of the johnson county war. Journal of Economic History, 67:1, 2007.

[14] Elinor Ostrom. Governing the Commons: The evolution of institutions for collective action. Cambridge University Press, Cambridge, England, 1990.

[15] Lovejoy Sakala. Cattle rustling decimates herd. The Zimbabwean, April 1 st 2011.

[16] Glenn G. Stevenson. Comon Property Economics: A General Theory and Land Use. Cambridge University Press, Cambridge, UK, 1991.

[17] J. R. Umbeck. Might makes rights: A theory of the formation and initial distribution of property rights. Economic Inquiry, 19(1):38-59, 1981.

[18] John C. Weaver. The Great Land Rush and the Making of the Modern World, 1650-1900. McGill-Queen's University Press, 2003. 
[19] John R Wennersten. The Oyster Wars of Chesapeake Bay. Eastern Branch Press, Washington, 2007. 